\title{
Using a Clinical Diary and Learning Journal to Improve Reflective Competence for Nursing Students in Vietnam
}

\author{
Nguyen Hung Hoa ${ }^{1, *}$, Ngo Anh Tuan ${ }^{2}$ \\ ${ }^{1}$ Nurse Anesthetist Department, Ho Chi Minh University of Medicine and Pharmacy (UMP), Vietnam \\ ${ }^{2}$ Institute of Technical Education, Ho Chi Minh University of Technology and Education (HCMUTE), Vietnam
}

Received April 9, 2021; Revised June 7, 2021; Accepted June 20, 2021

\begin{abstract}
Cite This Paper in the following Citation Styles
(a): [1] Nguyen Hung Hoa, Ngo Anh Tuan, "Using a Clinical Diary and Learning Journal to Improve Reflective Competence for Nursing Students in Vietnam," Universal Journal of Educational Research, Vol. 9, No. 7, pp. 1464 - 1471, 2021. DOI: 10.13189/ujer.2021.090712.
\end{abstract}

(b): Nguyen Hung Hoa, Ngo Anh Tuan (2021). Using a Clinical Diary and Learning Journal to Improve Reflective Competence for Nursing Students in Vietnam. Universal Journal of Educational Research, 9(7), 1464 - 1471. DOI: 10.13189/ujer.2021.090712.

Copyright $\odot 2021$ by authors, all rights reserved. Authors agree that this article remains permanently open access under the terms of the Creative Commons Attribution License 4.0 International License

\begin{abstract}
Introduction: In nursing education, reflective competence is evaluated by achieving tacit knowledge, mentioning the patient's attitude, and applying flexible skills. Writing clinical diaries and learning journals can enhance reflective competence. Aims: The paper aims to use a clinical diary and learning journal for improving reflective competence. Methodology: 17 nursing students were randomly divided into controlled group and experimental group. The controlled group learned with the current teaching method, while the experimental group used a formed clinical diary and structured learning journal. After two weeks, all participants were asked to self-evaluate by scoring the implementation frequency and evaluating the teacher's clinical score. Results: The clinical score is higher in the experimental group $(9.13 \pm$ $0.52)$ than in the control group $(8.39 \pm 0.65)$. The difference between the controlled group and the experimental group was significant, with $\mathrm{p}=0.022<0.05$. The mean of reflective competence in the experimental $(3.98 \pm 0.47)$ is higher than the mean in the controlled group $(2.92 \pm 0.16)$. The difference in reflective competence between the controlled and experimental groups has been highly significant, with $\mathrm{p}<0.001$. Conclusion: Writing a clinical diary and learning journal effectively improves reflective competence, helping nursing students achieve tacit knowledge, mention the patient's attitude, and apply flexible skills.
\end{abstract}

Keywords Reflective Competence, Clinical Diary, Learning Journal, Nursing Student

\section{Introduction}

Nursing students have to refresh and update their knowledge and skills. Preparing professionals can help students solve problems in a future career [1]. In nursing education, the students have to learn based on the clinical situation. Reflection was the best competence for students to recognize themselves in the learning environment, which helped students apply their knowledge flexibly in different circumstances [2]. This paper used Clinical Diary and Learning Journal to improve Reflective Competence for Nursing Students in Vietnam.

\section{Reflective Competence}

Reflective capacity is regarded by many as an essential characteristic of professional competence [3] as reflective competence is an essential attribute for developing autonomous, critical, and advanced practitioners. In learning, reflective competence improves self-knowledge, relating experience to knowledge, self-reflection, and self-regulation [4]. In nursing education, reflective competence enhances nursing care and better understands their actions, developing their professional skills with more emotions [5]. In other research, reflective competence highlighted the method to help them better understand themselves, engage in self-reflection about the 
learning process, optimize their strengths, and discover additional training needs, along with searching for continuous improvement.

As a result, in this paper, reflective competence is defined to achieve tacit knowledge, mention the patient's attitude, and apply flexible skills. Tacit knowledge cannot express by verbal language, which is achieved by combining experience and personal knowledge. The tacit knowledge helps improve the self-knowledge of the students. The knowledge from experience helps students focus on the patient's attitude, which is one of the critical factors to the patient's recovery; therefore, concerning ones while taking care of patients helps the nursing students improve the caring practice's effectiveness. Before applying in a new circumstance, the nursing student has had self-reflection and self-regulation, and as a result, a checklist for nursing care skills should be applied flexibly, depending on the patients' conditions or the situation.

The instructors have to design the learning activity, the learning diary, and the learning journal [6,7]. The learning diary and the learning journal stimulate the ability to achieve tacit knowledge, mention the patient's attitude and apply the flexible skills in students by increasing the thinking back of the student's experience.

\section{Learning Diary and Learning Journal}

Practice-based or clinical placements are highly valued for linking a theory to practice and enabling students to meet graduate outcomes. Post-practicum, the period immediately following clinical experiences, is when students have an opportunity to share, compare and engage critically in considering how these experiences impact their learning [8].

Learning diary offers a strategy that can help learners review what they learn with their everyday practice. It can also help them control their learning and develop insight into how they learn [9]. Learning journals are recognized as a powerful tool in promoting active learning among nursing students. Essentially, nurse educators strive to encourage students to think about past experiences, current situations, and expected outcomes of their actions so that they can explain what they do in the clinical setting and why [10].

Current nursing education focused on helping students develop into independent, critical thinkers. A reflective learning journal is one method to help students review their practice, learn from practicum experience, self-evaluate, and gain depth in nursing knowledge [11].

Tang (2000) implement a case study where reflective learning journals in the form of reflective learning diaries were used to facilitate and assess reflective competence in a group. As one of the learning activities, the students must keep reflective learning diaries of their learning modules. The students were also required to select and include two diaries as a reflective learning journal to submit for assessment [12].

Evidence from both the student's reported experience and the information in the diaries shows a reflective learning diary and reflective learning journal are helpful tools in facilitating reflective competence. Writing the diaries requires the students to reflect on the professional learning activities that have taken place, provides an opportunity for them to search for and express their learning in a personal way, to relate and apply their learning to their professional and assessment practice [12].

The participants apply Gibbs's cyclical model of reflection (1998) and write Clinical Diary at the evaluation phase and Learning Journal at the action plan phase to improve the reflective competence. In addition, the research applies a quantitative study to compare pre-test scores and post-test scores of reflective competence.

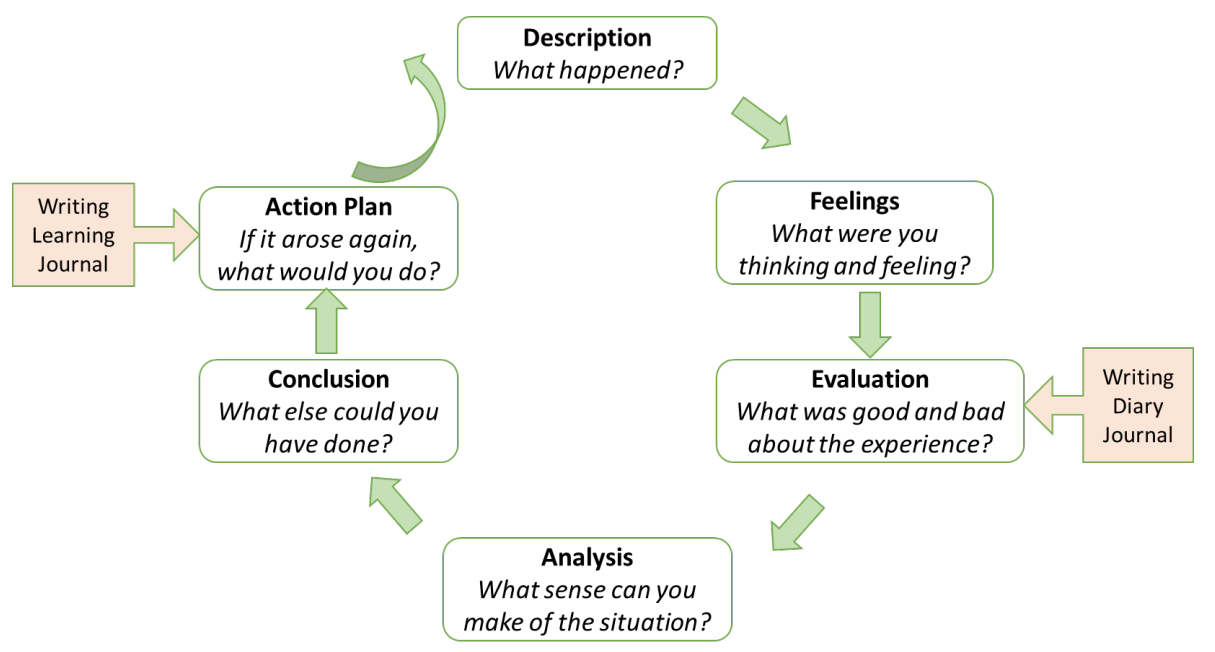

Figure 1. Gibbs's cyclical model of reflection [13] 
Diary Journal's content is the questions that give the student a chance to glance at their experience. This writing helps students gain self-knowledge and focus on the patient's attitude to improve the caring practice's effectiveness. The content of the Learning Journal is the questions that students need to explain the new decisions for the subsequent circumstance in the clinic. Thus, the Diary Journal and Learning Journal are the products that are used to prove that participants achieved their reflection.

\section{Conceptual Framework}

This study's conceptual framework was to present the learning diary's role and the learning journal to increase the reflective competence and the effectiveness of the reflective competence on knowledge, skill, and attitude (Figure 2).

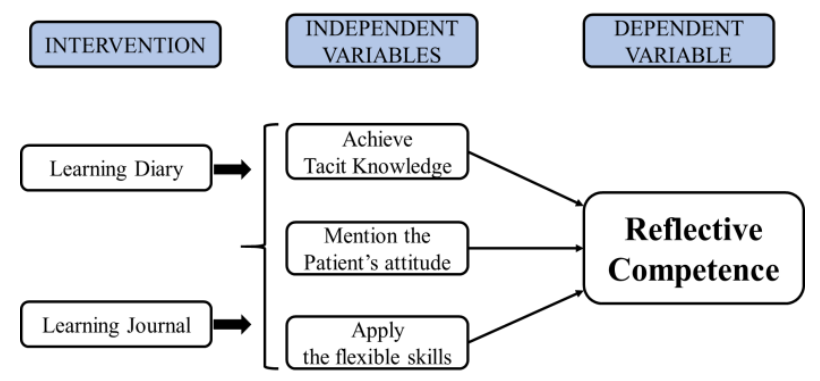

Figure 2. Conceptual Framework

Reflective competence is the dependent variable controlled by three independent variables: achieving tacit knowledge, mentioning the patient's attitude, and applying flexible skills. The independent variables can improve by using interventions which are the learning diary and the learning journal. The learning diary helps students integrate the clinical and administrative knowledge necessary for beginning practice [11]. Participants are asked to keep a learning diary about events in their practicum day, how they feel about those events, how the situation might have changed, and what they have learned. In addition, faculty members or other students offer evaluative feedback and suggestions for future actions. The learning journal is the ability to examine one's actions and experiences with the outcome of developing one practice and enhancing clinical knowledge.

\section{Research Method}

\section{Research design and sample}

The research applies a quantitative study to compare the score of reflective competence self-evaluated by students and the clinical score evaluated by a clinical teacher for the experimental and control groups. The participants should be satisfied with the inclusion and the exclusion.

\section{The inclusion:}

- Participants are practicing in the clinical

- All techniques, which participants practice, were learned the theory and fluently practice in the skill labs room.

- Participants implement the techniques in the patients with permission.

\section{The exclusion:}

- Participants did not follow the structure of writing instruction.

- Participants did not submit writing on time.

All participants in two clinical practicum groups in two hospitals were chosen with the agreement after understanding the research. The control group with 9 participants learned in the clinical environment in 2 weeks with the standard learning method. The experimental group with 8 participants learned in the clinical environment in weeks to help the structured learning diary and the structured learning journal increase reflective competence.

In the experimental group, the structured learning diary was written every day (Monday to Friday) after taking part in the clinic. In addition, every weekend, all participants were asked to write a structured learning journal — a research instrument.

The experience group participants received a learning diary and learning journal for two weeks and the deadline for keeping the writing activity. At the end of the experiment, all participants evaluated the reflective competence to assess themselves. In addition, the participants had evaluated the clinical abilities of the clinical teacher. 
Table 1. The form of evaluation for the reflective competence

\begin{tabular}{|c|c|c|}
\hline No & Criteria for reflective competence & Score \\
\hline \multicolumn{3}{|c|}{ Achieve the tacit knowledge } \\
\hline 1 & Share their applied knowledge & \\
\hline 2 & Associate the past situations & \\
\hline 3 & Analyze the facing in the situation & \\
\hline 4 & Adjust themselves to overcome the difficulties in the past situations & \\
\hline \multicolumn{3}{|c|}{ Mention the patient's attitude } \\
\hline 5 & Take the patient's attitude & \\
\hline 6 & Explain the causes of the patient's attitude & \\
\hline 7 & Suggest the strategies for improving the patient's attitude & \\
\hline 8 & Analyze these strategies' advantage and disadvantage & \\
\hline 9 & Evaluate the own competence to improve the patient's attitude in this situation & \\
\hline 10 & Adjust themselves to help the patients increase the patient's attitude & \\
\hline \multicolumn{3}{|c|}{ Apply the flexible skills } \\
\hline 11 & Describe the advantage and disadvantage in the new situation & \\
\hline 12 & Present the experience which overcomes the similar situation in the past & \\
\hline 13 & Compare the advantage and disadvantage between 2 situations & \\
\hline 14 & Analyze and explain the changed activity in a new situation & \\
\hline 15 & Adjust themselves to implement the new situation & \\
\hline \multicolumn{2}{|c|}{ 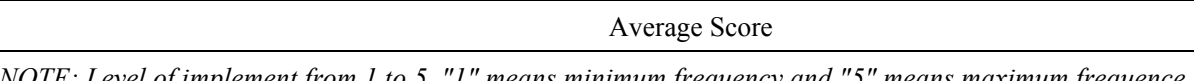 } & $\ldots . . / 5$ \\
\hline
\end{tabular}

Table 2. The range of average score for reflective competence

\begin{tabular}{|l|l|l|}
\hline \multicolumn{2}{|l|}{ Level of the reflective competence } & \multirow{2}{*}{ Range of the Average Score } \\
\hline The reflective competence & Frequency of using the activity of reflective competence & \\
\hline \multirow{3}{*}{ Not achieve } & Never & $1.0-1.8$ \\
\cline { 2 - 3 } & Hardly & $1.9-2.6$ \\
\cline { 2 - 3 } & Sometimes & $2.7-3.4$ \\
\hline \multirow{3}{*}{ Achieve } & Usually & $3.5-4.2$ \\
\cline { 2 - 3 } & Always & $4.3-5.0$ \\
\hline
\end{tabular}

The students have to self-evaluate the frequency of reflective activity in 2 weeks. The Five - Likert Scale was to use for this table (Table 1). In the end, the average score of 15 criteria was calculated. Based on the average score's value, the reflective competence determined the achievement or not (Table 2).

\section{Determine variable and collect data}

The clinical diary and learning journal applied using the structured diary and the structured journal to improve reflective learning. The reflective competence consists of achieving tacit knowledge, mentioning the patient's attitude, and applying flexible, caring skills.

The intervention is the writing of a clinical diary and learning journal. The clinical diary requires writing every day after finishing the day's practicum in the clinic. The learning journal asked to write weekly about the Clinical Diary evaluation for a week with five days. Clinical diary and learning journals are structured by the opened questions created by the teacher.

Dependent variables were the reflective competence created by independent variables that achieved tacit knowledge, mentioning the patient's attitude, and applying flexible skills.

All participants in the control group and the experimental group evaluated the clinical practicum by ten scales with the current method after two weeks in the clinic. In addition, every student in 2 groups evaluated the 15 criteria for reflective competence after two clinical practicum weeks.

The 15 criteria of reflection competence's 
questionnaires answered Five-Point Likert Scale with 1 point means never implement the criteria, and 5 points mean consistently implement the criteria. The mean of the three criteria calculated the Score in Achieving Tacit Knowledge. The mean of 7 criteria calculated the Score in Mentioning the Patient's attitude. The mean of 5 criteria calculated the Score in Applying the flexible skills. The mean of Achieving Tacit Knowledge, Applying the flexible skills, and Applying the flexible skills was the Score of Reflective Competence.

\section{Ethical Consideration}

The Ethics Council approved this research of the University of Medicine and Pharmacy at Ho Chi Minh City, Vietnam. After we clearly explained the study's objectives, the participants voluntarily signed the consent form to participate in the study. Furthermore, we ensured that participants were not affected by any benefits in their work.

\section{Findings}

\section{Describing the data}

The study applied for 17 students divided into two groups. The experimental group had eight students $(47 \%$ in participants), and the control group had nine students (53\% in participants). Each group had a clinical teacher who worked in the hospital, commenting about their learning diary and learning journal in 2 weeks. In addition, a teacher from the university in each group helped students achieve the university's criteria and recognize the gap between the theory and the practice.
Table 3. The percentage of the participants

\begin{tabular}{|c|c|c|c|}
\hline Participant & Group & Quality & Percentage \\
\hline \multirow{2}{*}{ Student } & Experimental & 8 & $47 \%$ \\
\cline { 2 - 4 } & Control & 9 & $53 \%$ \\
\hline
\end{tabular}

\section{The final score of clinical practicum}

The final score was evaluated by the university criteria for two weeks in clinical practicum with 10 -scale. The results showed that the mean score in the experimental group $(9.13 \pm 0.52)$ higher than the mean score in the control group $(8.39 \pm 0.65)$. The difference between the controlled and experimental groups was significant, with $\mathrm{p}$ $=0.022<0.05$.

With the null hypothesis $\left(\mathrm{H}_{0}\right): \mu 1=\mu 2$ ( $\mu 1$ : the controlled mean of the score; $\mu 2$ : the experimental mean of the score). Based on Table 4, the result showed that the $t_{\alpha}$ for $d f=15$ is $t_{\alpha}=2.95$ with a confident interval was $99 \%$ [14]. The null hypothesis was rejected due to t-value $=5.328>t_{\alpha}$. There was a difference in the mean between the controlled group and the experimental group. Writing the clinical diary and the learning journal helped the nursing students improve the confidence interval's clinical practicum score by $99 \%$.

\section{Reflective competence}

The results showed that the mean of three criteria in the reflective competence and the mean of reflective competence were under 3.0 in the controlled group and around 4.0 in the experimental group (Figure 2). Thus, the results mean that the experimental group achieved reflective competence and did not achieve in the controlled group.

Table 4. The final score of clinical practicum

\begin{tabular}{|c|c|c|c|c|c|c|}
\hline \multirow[b]{2}{*}{ Variable } & \multicolumn{2}{|c|}{ Control $(n=09)$} & \multicolumn{2}{|c|}{ Experimental $(\mathrm{n}=08)$} & \multirow[b]{2}{*}{ t-value } & \multirow[b]{2}{*}{ p-value } \\
\hline & Mean & $\begin{array}{l}\text { Standard } \\
\text { deviation }\end{array}$ & Mean & $\begin{array}{l}\text { Standard } \\
\text { deviation }\end{array}$ & & \\
\hline Mean Score & 8.39 & 0.65 & 9.13 & 0.52 & 2.557 & $0.022 *$ \\
\hline
\end{tabular}




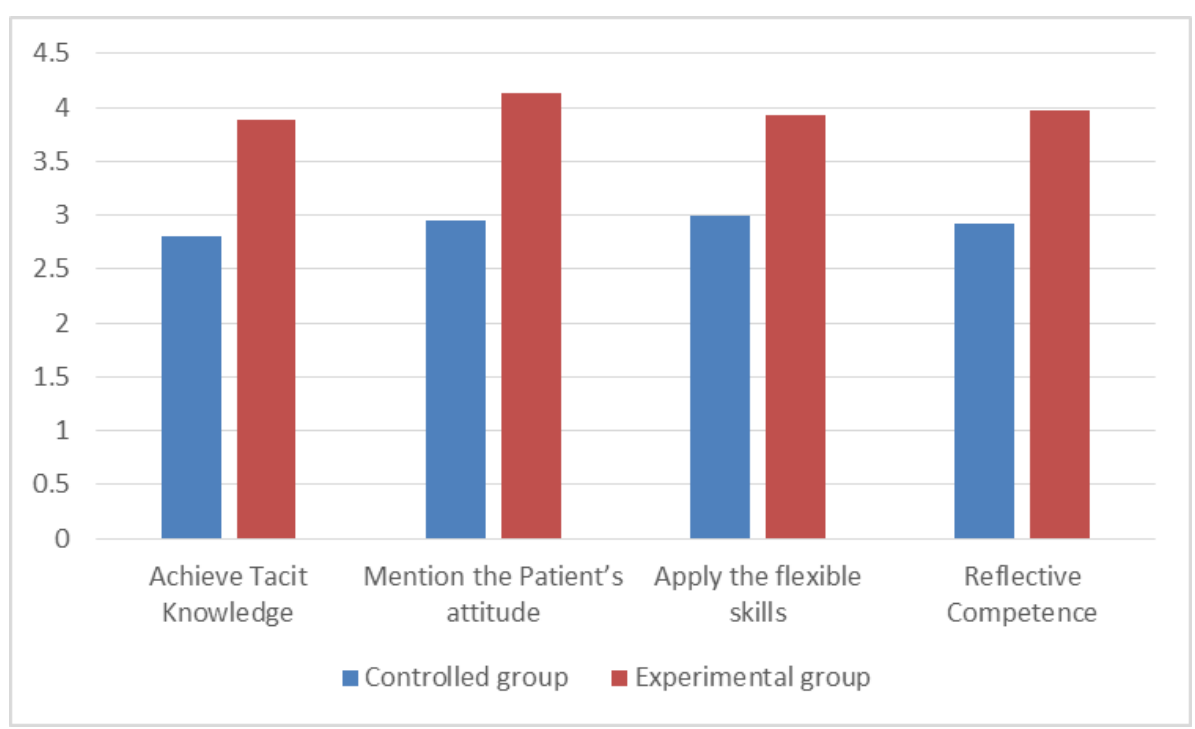

Figure 2. The mean of reflective competence

Table 5. The mean of reflective competence

\begin{tabular}{|c|c|c|c|c|c|c|c|}
\hline \multirow{3}{*}{ No. } & \multirow{3}{*}{$\begin{array}{l}\text { Criteria of Reflective } \\
\text { Competence }\end{array}$} & \multicolumn{4}{|c|}{ Mean } & \multirow{3}{*}{ T-value } & \multirow{3}{*}{ P-value } \\
\hline & & \multicolumn{2}{|c|}{ Control group $(n=09)$} & \multicolumn{2}{|c|}{ Experimental group $(n=08)$} & & \\
\hline & & Mean & Standard deviation & Mean & Standard deviation & & \\
\hline 1 & Achieve Tacit Knowledge & 2.81 & 0.41 & 3.88 & 0.53 & 4.621 & $.000^{* *}$ \\
\hline 2 & Mention the Patient's attitude & 2.95 & 0.20 & 4.14 & 0.55 & 5.829 & $.000^{* *}$ \\
\hline 3 & Apply the flexible skills & 3.00 & 0.22 & 3.93 & 0.47 & 5.328 & $.000^{* *}$ \\
\hline & Reflective Competence & 2.92 & 0.16 & 3.98 & 0.47 & 6.014 & $.000^{* *}$ \\
\hline
\end{tabular}

* - significant; ** - highly significant

The t-test was used to test the difference between the controlled group and the experimental group: (1) the mean of three criteria in the reflective competence and (2) the mean of reflective competence (Table 5). The results showed that it rejected the null hypothesis: there was the same mean of the three criteria in the reflective competence and reflective competence. It means that the difference in reflective competence between the controlled and experimental groups has been highly significant, with $p<0.001$. Therefore, the intervention, which is a learning diary and learning journal, can improve reflective competence. The improvement of reflective competence helped the nursing students connect with their patients [15].

Three characteristics created the reflective competence: Achieving Tacit Knowledge, Mentioning the patient's attitude, and Applying flexible skills. Based on the means of these characters in the experimental group, the order impact of three characteristics to the reflective competence was the Mentioning the patient's attitude (Mean $=4.14 ; \mathrm{SD}=0.55$ ), the Applying the flexible skills (Mean $=3.93 ; \mathrm{SD}=0.47$ ) and the Achieving Tacit Knowledge $($ Mean $=3.88 ; \mathrm{SD}=0.53$ ). The mean of mentioning the patient's attitude was higher than the mean of reflective competence $(4.14>3.98)$. This result means writing improved the mentioning of the patient's attitude. Writing the clinical diary and the learning journal let nursing students have more time to consider-why they did or plan to do a clinical practicum, which helped students explore emotions, feelings, reactions, and knowledge for the following situation.

With the null hypothesis $\mathrm{H}_{0}: \mu_{1}=\mu_{2}\left(\mu_{1}\right.$ : the controlled mean; $\mu_{2}$ : the experimental mean). Based on Table 5 , the result showed that (1) the $t \alpha$ for $\mathrm{df}=15$ is $t \alpha=2.95$ with the confidence interval was $99 \%$ [14]. The null hypothesis was rejected due to t-value $=4.621>\mathrm{t} \alpha$. There was a difference in the mean between the controlled group and the experimental group. It inferred that writing the clinical diary and the learning journal helped the nursing students achieve the tacit knowledge with the confidence interval being $99 \%$; (2) the $t \alpha$ for $\mathrm{df}=8.699$ is $t \alpha=3.25$ with a confidence interval of $99 \%$ [14]. The null hypothesis was rejected due to $\mathrm{t}$-value $=5.829>\mathrm{t} \alpha$. There was a difference in the mean between the controlled group and the experimental group. It inferred that writing the clinical diary and the learning journal helped the nursing students mention the patient's attitude with the confidence interval was $99 \%$; (3) the $t \alpha$ for $\mathrm{df}=15$ is $t \alpha=2.95$ with confident interval was $99 \%$ [14]. The null hypothesis was rejected due to $t$-value $=5.328>t \alpha$. There was a difference in the 
mean between the controlled group and the experimental group. It inferred that writing the clinical diary and the learning journal helped the nursing students apply the flexible skills with the confidence interval was $99 \%$.; and (4) the ta for $\mathrm{df}=8.481$ is $\mathrm{t} \alpha=3.25$ with confident interval was $99 \%$ [14]. The null hypothesis was rejected due to $t$-value $=6.014>$ t $\alpha$. There was a difference in the mean between the controlled group and the experimental group. Writing the clinical diary and the learning journal helped the nursing students improve the reflective competence, with the confidence interval being $99 \%$.

\section{Discussion}

In Vietnam, reflective competence, which is understood as the critical competence for a nursing student at the graduated examination, proved the students achieve the tacit knowledge, mention the patient's attitude, and apply flexible skills. Therefore students did not learn reflective writing skills, and it happened as a natural capacity. Jasper (1999) determined that reflective writing skills that were not a natural capacity needed to learn. To facilitate reflective writing, nursing students have to accept writing as a learning strategy or tools which develop analytical abilities, critical abilities and identify personal and professional growth [16], by writing the clinical diary and learning journal, the ability to analyze the theory in clinical to be suitable for the patient's condition to achieve the tacit knowledge for own nursing students. As a result, nursing students can suggest a way to improve caring checklists. Writing the clinical diary and the learning journal helped the nursing students adjust their knowledge by analyzing and test the suggestion and finally changed the student's knowledge. It is suitable to Naber's study results, which stated that reflective writing allows students to combine clinical experiences and knowledge with material better to understand both practice and instruction [17]. Moreover, reflective writing has fostered nurses' clinical, relational, and ethical competence and promotes self-knowledge [18]_ building up students' self-confidence and increasing interaction. Instructors concerned with achieving tacit knowledge improved self-confidence [19].

Writing makes students have time to think back on what happened to the patient, which helps them mention their attitude. Through writing activity, the nursing student determined the patient's attitude and improved the patient's attitude. This result focused on Levine's study showed that reflective writing promoted greater self-awareness and provided an emotional outlet [20]. Themes of caring behavior toward patients and writing help nursing students focus on mentioning the patient's attitude, which helps them understand the patient's need and enhance caring [19].
The nursing students adjusted themselves to satisfy their situation based on the clinical diary and the learning journal. The nursing students analyzed the cause of the problem, synthesized the hospital condition and their knowledge, and evaluated their clinical observation to suggest a suitable solution for them in their new situation. This evidence proved that reflective learning was achieved because Toros's study stated that reflective competence improved personal and professional awareness and professional growth promoted new meanings and solutions and learning from experiences. It also enhanced personal development (self-knowledge, self-awareness, self-consciousness) and professional development (constructing a new solution, understand the client) [21]. The themes of enhancing students' self-development and overcoming writing difficulty were applying flexible skills [19]. Through reflective writing, the students learned to organize their thoughts and actions according to their worldview.

Reflective writing helps students gain insights into the profession and clinical practices. Epp (2008) stated that reflective journaling is an appropriate tool to promote reflective competence to learn from undergraduate nursing education practice [22]. They were applying the flexible skills, mentioning the patient's attitude, and achieving tacit knowledge in this paper, improved by writing the clinical diary and learning journal formed in the clinical caring journal. Kuo (2011) implemented a new teaching strategy that used a clinical caring journal (CCJ) in the clinical practicum. Researchers used content analysis to sort interview data into six themes: caring behavior toward patients, enabling students' reflective caring abilities, building up students' self-confidence, increasing interaction between students and instructors, enhancing students' self-development, and overcoming writing difficulty [19].

\section{Conclusions}

The clinical diary and the learning journal are reflective writing that improved the reflective competence of nursing students. Based on the statistical value and nursing students' statement, achieving tacit knowledge, mentioning the patient's attitude, and applying the flexible skills were investigated and improved reflective competence in writing.

\section{Limitation of the Study}

Due to the participants' practicing on patients, the participant numbers are too small. Therefore, a study with a relatively small sample size may not have the statistical power to expose such a small effect, possibly resulting in a type II error. 


\section{Recommendation}

It suggested that future research with more significant participant numbers. The future study will present more the relationship between reflective competence and diary structure such as gender, ages, the character of assessment (formative or summative), and individual learning environments.

\section{REFERENCES}

[1] N. H. Hoa and N. A. Tuan, "Stimulating the Students' Reflection," (in English), IOSR Journal of Research \& Method in Education (IOSR-JRME), vol. 9, no. 6, pp. 18-21, 2019.

[2] N. H. Hoa and N. A. Tuan, "Learning Stratergies for Improving Reflection in Engineering Education in Vietnam," IOSR-Journal of Research \& Method in Education (IOSR-JRME), vol. 10, no. 1, pp. 06-09, 2020.

[3] K. Mann, J. Gordon, and A. MacLeod, "Reflection and reflective practice in health professions education: a systematic review," (in eng), Adv Health Sci Educ Theory Pract, vol. 14, no. 4, pp. 595-621, Oct 2009.

[4] J. Colomer, "Reflective learning in higher education: A comparative analysis," Social and Behavioral Sciences pp. $364-370,2013$.

[5] L. Caldwell, "The importance of reflective practice in nursing," International Journal of Caring Sciences, vol. 6 , no. 3, p. 319, 2013.

[6] C. Bradbury-Jones, S. M. Hughes, W. Murphy, L. Parry, and J. Sutton, "A new way of reflecting in nursing: the Peshkin Approach," (in En), $J$ Adv Nurs, vol. 65, no. 11, pp. 2485-93, Nov 2009.

[7] J. Kok and M. M. Chabeli, "Reflective journal writing: how it promotes reflective thinking in clinical nursing education: a students' perspective," (in En), Curationis, vol. 25, no. 3, pp. 35-42, Aug 2002.

[8] L. Sweet, J. Bass, M. Sidebotham, J. Fenwick, and K. Graham, "Developing reflective capacities in midwifery students: Enhancing learning through reflective writing," Women and Birth, vol. 32, no. 2, pp. 119-126, 2019/04/01/ 2019.

[9] A. Grant, A. Berlin, and G. K. Freeman, "The impact of a student learning journal: a two-stage evaluation using the Nominal Group Technique," Medical teacher, vol. 25, no. 6, pp. 659-661, 2003.
[10] K. Thorpe, "Reflective learning journals: From concept to practice," Reflective practice, vol. 5, no. 3, pp. 327-343, 2004.

[11] A. Fortson and R. Sisk, "Reflective Journaling as Assessment and Teaching," in From the REAP International Online Conference on Assessment Design for Learner Responsibility, 2007.

[12] C. Tang, "Reflective diaries as a means of facilitating and assessing reflection," the Pacific Rim Conference on Higher Education Planning and Assessment, Hawaii, USA2000.

[13] G. Gibbs, "Learning by doing: A guide to teaching and learning methods," (in En), Further Education Unit, 1988.

[14] N. N. Rạng, Thiết kế nghiên cưu và thống kê y học. Nhà xuất bản y học, 2012.

[15] D. Coleman and D. S. Willis, "Reflective writing: The student nurse's perspective on reflective writing and poetry writing," Nurse education today, vol. 35, no. 7, pp. 906-911, 2015 .

[16] M. A. Jasper, "Nurses' perceptions of the value of written reflection," (in eng), Nurse Educ Today, vol. 19, no. 6, pp. 452-63, Aug 1999.

[17] J. Naber and L. Markley, "A guide to nursing students' written reflections for students and educators," Nurse education in practice, vol. 25, pp. 1-4, 2017.

[18] L. Montagna, C. Benaglio, and L. Zannini, "[Reflective writing in nursing education: background, experiences and methods]," (in ita), Assist Inferm Ric, vol. 29, no. 3, pp. 140-52, Jul-Sep 2010. La scrittura riflessiva nella formazione infermieristica: background, esperienze e metodi.

[19] C. L. Kuo, M. Turton, S. F. Cheng, and J. Lee-Hsieh, "Using clinical caring journaling: nursing student and instructor experiences," (in eng), J Nurs Res, vol. 19, no. 2, pp. 141-9, Jun 2011

[20] R. B. Levine, D. E. Kern, and S. M. Wright, "The impact of prompted narrative writing during internship on reflective practice: a qualitative study," Advances in health sciences education, vol. 13, no. 5, pp. 723-733, 2008.

[21] K. Toros and M. Medar, "Social Work Students' Thoughts on Self-Reflection: A Qualitative Study Based on Reflective Journaling," International Journal of Humanities and Social Science, vol. 5, p. 8, 2015.

[22] S. Epp, "The value of reflective journaling in undergraduate nursing education: a literature review," (in eng), Int $J$ Nurs Stud, vol. 45, no. 9, pp. 1379-88, Sep 2008. 